\title{
"Motorcycle Ambulance" Policy to Promote Health and Sustainable Development in Large Cities
}

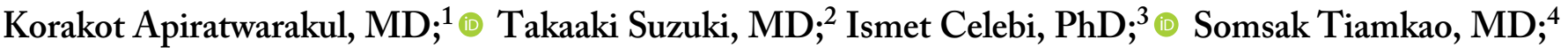 \\ Vajarabhongsa Bhudhisawasdi, $\mathrm{MD} ;{ }^{1}$ Chatkhane Pearkao, $\mathrm{PhD} ;{ }^{5}$ Kamonwon Ienghong, $\mathrm{MD}^{1}{ }^{(1)}$
}

1. Department of Emergency Medicine, Faculty of Medicine, Khon Kaen University, Khon Kaen, Thailand

2. Department of Emergency and Critical Care Medicine, University of Tsukuba Hospital, Tsukuba, Japan

3. Department of Paramedic, Gazi University, Ankara, Turkey

4. Department of Medicine, Faculty of Medicine, Khon Kaen University, Khon Kaen, Thailand

5. Department of Adult Nursing, Faculty of Nursing, Khon Kaen University, Khon Kaen, Thailand

Correspondence:

Kamonwon Ienghong, MD 123 Department of Emergency Medicine Faculty of Medicine, Khon Kaen University Khon Kaen, 40002, Thailand

E-mail: kamonwan@kku.ac.th

Conflicts of interest/funding: This research was funded by Research and Graduate Studies, Khon Kaen University, Thailand (RP64-7/ 002). The authors have no conflicts of interest to disclose.

Keywords: cardiac arrest; emergency health services; Emergency Medical Services; health policy; motorcycles; response time

\author{
Abbreviations: \\ AED: automated external defibrillator \\ AEMT: advanced emergency medical technician \\ COVID-19: coronavirus disease 2019 \\ CPR: cardiopulmonary resuscitation \\ EMS: Emergency Medical Services \\ EMT: emergency medical technician \\ MICE: Meetings, Incentives, Conventions, and \\ Exhibitions \\ Motorlance: motorcycle ambulance
}

Received: August 24, 2021

Revised: September 23, 2021

Accepted: September 29, 2021

\begin{abstract}
Introduction: Motorcycles can be considered a new form of smart vehicle when taking into account their small and modern structure and due to the fact that nowadays, they are used in the new role of ambulance to rapidly reach emergency patients in large cities with traffic congestion. However, there is no study regarding the measuring of access time for motorcycle ambulances (motorlances) in large cities of Thailand.

Study Objective: This study aims to compare access times to patients between motorlances and conventional ambulances, including analysis of the use of automated external defibrillators (AEDs) installed on motorlances to contribute to the sustainable development of public health policies.

Methods: A cross-sectional study was conducted on all motorlance operations in Emergency Medical Services (EMS) at Srinagarind Hospital, Thailand from January 2019 through December 2020. Data were recorded using a national standard operation record form for Thailand.

Results: Two hundred seventy-one motorlance operations were examined over a two-year period. A total of $52.4 \%(\mathrm{~N}=142)$ of the patients were male. The average times from dispatch to vehicle (motorlance and traditional ambulance) being en route (activation time) for motorlance and ambulance in afternoon shift were 0.59 minutes and 1.45 minutes, respectively $(\mathrm{P}=.004)$. The average motorlance response time in the afternoon shift was 6.12 minutes, and ambulance response time was 9.10 minutes at the same shift. Almost all of the motorlance operations (97.8\%) were found to have no access to AED equipment installed in public areas. The average time from dispatch to AED arrival on scene (AED access time) was 5.02 minutes.

Conclusion: The response time of motorlances was shorter than a conventional ambulance, and the use of AEDs on a motorlance can increase the chances of survival for patients with cardiac arrest outside the hospital in public places where AEDs are not available.
\end{abstract}

Apiratwarakul K, Suzuki T, Celebi I, Tiamkao S, Bhudhisawasdi V, Pearkao C, Ienghong K. "Motorcycle Ambulance" policy to promote health and sustainable development in large cities. Prehosp Disaster Med. 2022;37(1):78-83.

\section{Introduction}

Motorcycles used as ambulances (motorlances) have been shown to greatly increase access to emergency patients. A study in many major cities around the world with traffic congestion found that motorlance access took less time than access with the traditional ambulance. ${ }^{1-3}$ Due to its structure as a small vehicle, it can more easily access small alleys, as well as being able to pass through gridlock traffic in confined areas. Motorlances must have a specific design, structure, color, and equipment installed inside. ${ }^{4,5}$ The color used for the vehicle must be a medical emergency color code RAL 1016 sulfur yellow, which is the color that reflects the most clearly on the traffic route for both people with typical vision and also for those with color blindness problems. Reflective stickers are installed on the sides of the motorlance to increase the visibility to other vehicles, which boosts the

\section{doi:10.1017/S1049023X21001345}

(C) The Author(s), 2021. Published by Cambridge University Press on behalf of the World Association for Disaster and Emergency Medicine. This is an Open Access article, distributed under the terms of the Creative Commons Attribution licence (https:// creativecommons.org/licenses/by/4.0/), which permits unrestricted re-use, distribution, and reproduction in any medium, provided the original work is properly cited. 
level of safety during the operation. A windshield is thought to prevent wind and dust that may blow onto the driver and includes the installation of a siren signal. As for drivers, they must pass a safety training course in driving and best practices of operation of the motorlance. Each operation consists of two members: the driver is an emergency medical technician (EMTs) or advanced emergency medical technicians (AEMTs) and the passenger is an emergency physician or nurse. ${ }^{6-8}$ Global Positioning System (GPS) navigation is used to reach emergency patients in the shortest possible time. ${ }^{9}$ In addition, the motorlances that are currently in the design and manufacturing stages are also equipped with an automated external defibrillator (AED) on the vehicle. ${ }^{10,11}$ Most of the motorlances will be used in the role of speeding up patient access and initial assessment, but there are no studies on the use of motorlance AEDs. ${ }^{6,12-20}$ Therefore, the authors were interested in exploring the possible changes to public health policy by assigning motorlances with AEDs to reach patients in large cities. It has the potential to play an important role in the development of sustainable health care policies.

Currently, AEDs in Thailand have been prescribed to be installed in public areas such as bus stations and shopping malls, but it has been found that there are still very few compared to the proportion of the area, which may be due to the high price of the device, approximately three thousand US dollars per device. ${ }^{21,22}$ Although there is a law in Thailand that requires an AED device to be available to be used in first aid. That means the general public can use this tool when seeing a patient undergoing an out-of-hospital cardiac arrest. Another problem that can be found is the use of an AED for people without knowledge and expertise, resulting in people in the community who do not dare to use such a tool, which can be a serious problem, especially in Thailand. ${ }^{23-25}$ Thailand does not specify or mandate a formal course for the use of an AED, but rather it is considered basic knowledge from the primary to secondary school level. The rate of use of such machines is low. Together with the installation of an AED in public areas, there are not enough machines. ${ }^{26,27}$ From the information of Khon Kaen Province, it was found that in Mueang District, which has a population of more than 400,000 people in an area of 953.4 square kilometers, there are less than 50 AED devices in public areas.

Khon Kaen Province is located in the northeastern region and has a population of approximately two million people. This city was grouped in the Meetings, Incentives, Conventions, and Exhibitions (MICE) provinces that are important to the country's economic development. ${ }^{28}$ It has important geography as a gateway connecting the route to Indochina. The important activities of MICE consist of $\mathrm{M}=$ Meetings, $\mathrm{I}=$ Incentives, $\mathrm{C}=$ Conventions, and $\mathrm{E}=$ Exhibitions. All the activities involve a large number of people, including the public health system that is directly and indirectly involved. ${ }^{29-31}$ Public health standards require large gatherings to include first aid units and AEDs. Due to various limitations, there are very few AEDs to compare with the size of Khon Kaen Province. Therefore, the idea of using motorlances to solve such shortage problems has been put forward.

The primary objective of this study was to compare the access time between traditional ambulance and motorlance. The secondary outcome was to identify the characteristic of unresponsive patients with AEDs used in motorlances.

\section{Methods}

\section{Design and Setting}

A retrospective study was conducted on all motorlance operations in Emergency Medical Services (EMS) at Srinagarind Hospital (medical school), Thailand from January 2019 through December 2020. This hospital has an average of 2,000 EMS operations per year. The area of study was in Mueang District, Khon Kaen Province, one of the groups in the designated MICE provinces.

\section{Participants}

All data regarding patients in the period of study treated with both traditional ambulance and motorlance delivery to access patients were collected. Cases with incomplete data and those that went out of EMS operation and did not find a patient were excluded from this study.

\section{Data Collection}

Data were recorded using a national standard operation record form for Thailand EMS consisting of demographic data (age, gender), operation time (activation time, response time), type of patients (trauma, non-trauma), type of first procedure on scene for all patients, time of AED access, and disposition of patients at hospital, which were recorded at the EMS database of Srinagarind Hospital.

A comparative descriptive review of motorlance and traditional ambulance operations in the EMS database of Srinagarind Hospital was undertaken to examine differences in the operation time and to identify the characteristic of unresponsive patients with AEDs used in motorlances. The two independent, well-trained emergency physicians were extracted and reviewed these data from the EMS database. After that, double data entry was performed. In case of non-matched data, the senior emergency physician was checked and collected the data.

\section{Definitions}

Activation time was defined as times from dispatch to vehicle (traditional ambulance and motorlance) being en route. Response time was defined as times from 1669-center (center for command-andcontrol EMS in Thailand) call receipt to arrival on scene. The AED access time was defined as time from dispatch to AED arrival on scene.

The time used for this study was determined by one synchronized clock which was located in the dispatch center. The dispatcher observed EMS operations via telemedicine. The time of each operation process is recorded by computer into the EMS database.

\section{Study Size}

The sample size was calculated based on the following formula. ${ }^{32}$ The estimate for $\mathrm{P}$ was made using data from a previously published study. ${ }^{16}$ The authors determined that a sample size of 271 would be required. Statistical analysis was performed with Khon Kaen University's license for IBM SPSS for Windows version 26.0 (IBM Corp.; Armonk, New York USA). Categorical data were presented as percentages and continuous data were presented using means and standard deviations. Univariate analysis was performed using a two-sample t-test for numerical data and a Chisquared test for comparing data between the groups

\section{Ethical Considerations}

Ethical approval was provided by the Khon Kaen University Ethics Committee for Human Research (HE641369). Requirement for informed consent from the patients was waived since patient 


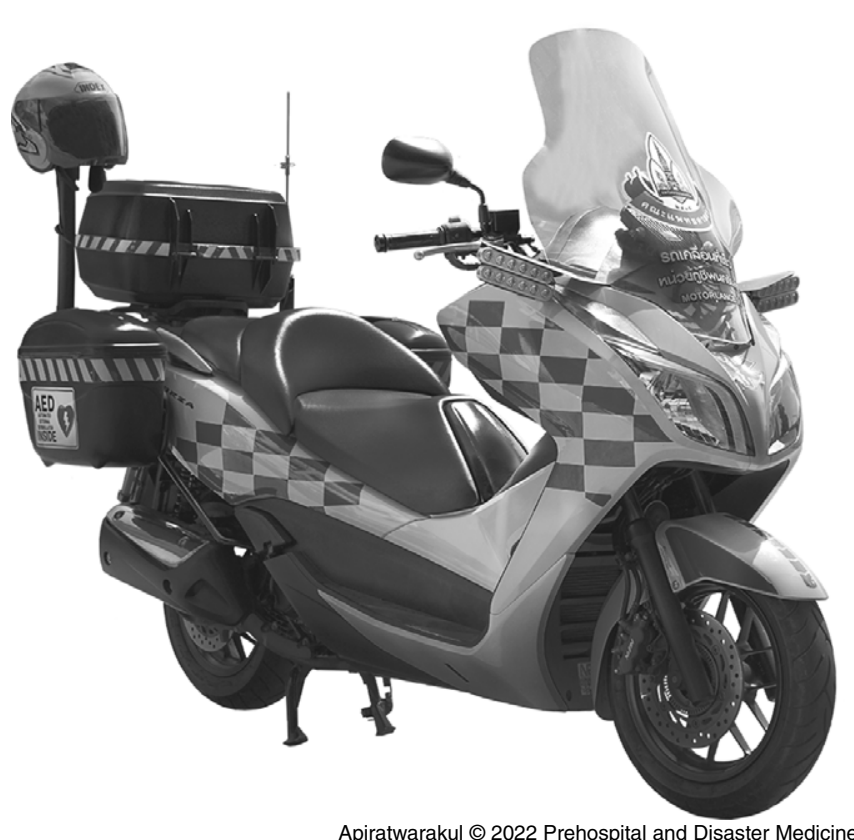

Figure 1. The Motorlance Model in Srinagarind Hospital, Thailand.

confidentiality protection had been guaranteed as patients were not identified by name, but rather by a unique study number.

\section{Motorlance}

Motorlances were modified from Honda New Forza 300 (Honda Motor Company, Ltd.; Tokyo, Japan) models (Figure 1). The width of the model is 75.30 -centimeters, length 216.60 -centimeters, height 118.90-centimeters, seat height 71.60-centimeters, ground clearance 13.90-centimeters, and has a net weight of 192 kilograms. The fuel used was gasohol 91, 95, or E20 and fuel tank capacity was 11.5 liters. The three device boxes were installed in the rear of the motorlance, one box on each the left and right sides, and one box behind the passenger seat. The box attached to the side of the motorlance was where the AED equipment was stowed for easy access. In addition, an airway management device and equipment related to stopping bleeding were prepared. The reflective stickers were installed to increase safety during operation, along with emergency sirens and with radio communication in the vehicle.

\section{Results}

Two hundred seventy-six motorlance operations were collected from the EMS database, of which five cases were excluded due to missing data. Hence, 271 motorlance operations were examined over a two-year period, the characteristics of which are shown in Table 1. A total of $52.4 \%(\mathrm{~N}=142)$ of the patients were male. The age group of the patients was mostly greater than 60 years of age (32.2\%). Operation time was most commonly performed (55.7\%) between afternoon shifts (4:00PM to 12:00AM). Trauma patients accounted for $56.1 \%$ of all cases in the period of study. The level of operation was advanced (with a doctor) in $22.9 \%$ of cases and basic (without a doctor) in $77.1 \%$ of cases.

The average times from dispatch to vehicle (motorlance and traditional ambulance) being en route (activation time) for motorlance and ambulance in the afternoon shift were 0.59 minutes and 1.45 minutes, respectively $(\mathrm{P}=.004$; Table 2$)$. The average motorlance

\begin{tabular}{|c|c|c|c|}
\hline Feature & Category & Frequency & Percent \\
\hline \multirow[t]{2}{*}{ Gender } & Male & 142 & 52.4 \\
\hline & Female & 129 & 47.6 \\
\hline \multirow[t]{6}{*}{ Age Group } & $<20$ & 3 & 1.1 \\
\hline & $20-29$ & 12 & 4.4 \\
\hline & $30-39$ & 25 & 9.2 \\
\hline & $40-49$ & 64 & 23.6 \\
\hline & $50-59$ & 80 & 29.5 \\
\hline & $\geq 60$ & 87 & 32.2 \\
\hline \multirow[t]{3}{*}{$\begin{array}{l}\text { Operation Time } \\
\text { (shift) }\end{array}$} & \begin{tabular}{|l|}
8 AM to 4 PM \\
(Morning) \\
\end{tabular} & 92 & 34.0 \\
\hline & $\begin{array}{l}4 \text { PM to } 12 \text { AM } \\
\text { (Afternoon) }\end{array}$ & 151 & 55.7 \\
\hline & $\begin{array}{l}12 \text { AM to } 8 \text { AM } \\
\text { (Night) }\end{array}$ & 28 & 10.3 \\
\hline \multirow{2}{*}{$\begin{array}{l}\text { Type of } \\
\text { Patients }\end{array}$} & Trauma & 152 & 56.1 \\
\hline & Non-Trauma & 119 & 43.9 \\
\hline \multirow{2}{*}{$\begin{array}{l}\text { Level of } \\
\text { Operations }\end{array}$} & With Doctor & 62 & 22.9 \\
\hline & Without Doctor & 209 & 77.1 \\
\hline
\end{tabular}

Apiratwarakul @ 2022 Prehospital and Disaster Medicine

Table 1. Characteristics of the Subjects with Motorlance Services $(\mathrm{N}=271)$

response time in the afternoon shift was 6.12 minutes, and ambulance response time was 9.10 minutes at the same shift.

In the period of study, 46 patients used AEDs in motorlances, the characteristics of whom are shown in Table 3. A total of 54.3\% of patients were male with most of those falling in the age group of greater than 60 years $(\mathrm{N}=25 / 46)$. The afternoon shift $(39.1 \%)$ was the most common time for the operation of AEDs use in motorlances to occur. Almost all of the motorlance operations (97.8\%) were found to have no access to AED equipment installed in public areas. The average time from dispatch to AED arrival on scene (AED access time) was 5.02 minutes. After an AED was used, the status of the patients when they arrived at the hospital was mostly in continuous resuscitation (95.7\%).

\section{Discussion}

This study examines the use of motorcycles in the sustainable development of public health policies. There are two main objectives: firstly, compare the duration of access to emergency patients between motorcycles with the traditional ambulance model; and second, analyze the use of the AED on the motorlance to reach emergency patients in areas without accessible AEDs in public places.

In the emergency operations with motorcycles, it was found that the population studied was similar in number of males and females. This is consistent with previous studies that found that emergency patients, for the most part, had no gender differences. $3,5,7,8,16$

In terms of the age groups who use motorlance services, it was found that the group that primarily used them was mostly over 60 years old, followed by the 50-to-59-year age group, which may be caused by data gathering between the years 2019-2020. It was during the outbreak of the coronavirus disease 2019 (COVID-19) virus. Most of the elderly did not want to go to the hospital or were restricted to travel by government policies and may be lacking regular medications, loss of follow-up, and waited until the service was needed through EMS. ${ }^{33,34}$ Another reason may be from the 


\begin{tabular}{|c|c|c|c|c|c|c|}
\hline \multirow{2}{*}{ Time } & \multirow{2}{*}{ Shift } & \multicolumn{2}{|c|}{$\begin{array}{c}\text { Motorlance (min) } \\
\mathrm{N}=\mathbf{2 7 1}\end{array}$} & \multicolumn{2}{|c|}{$\begin{array}{c}\text { Ambulance (min) } \\
\mathrm{N}=1860\end{array}$} & \multirow{2}{*}{ P Value } \\
\hline & & Mean & $95 \% \mathrm{Cl}$ & Mean & $95 \% \mathrm{Cl}$ & \\
\hline \multirow[t]{3}{*}{ Activation Time } & Morning & 0.57 & $(0.09-0.14)$ & 1.12 & $(0.11-0.22)$ & $.010^{\mathrm{a}}$ \\
\hline & Afternoon & 0.59 & $(0.08-0.15)$ & 1.45 & $(0.07-0.18)$ & $.004^{\mathrm{a}}$ \\
\hline & Night & 1.02 & $(0.20-0.26)$ & 1.55 & $(0.17-0.24)$ & $.014^{\mathrm{a}}$ \\
\hline \multirow[t]{3}{*}{ Response Time } & Morning & 5.42 & $(1.15-1.28)$ & 8.26 & $(1.10-1.46)$ & $<.001^{a}$ \\
\hline & Afternoon & 6.12 & $(1.37-1.44)$ & 9.10 & $(1.06-1.44)$ & $<.001^{a}$ \\
\hline & Night & 5.52 & $(1.96-2.05)$ & 8.20 & $(1.42-1.62)$ & $<.001^{\mathrm{a}}$ \\
\hline
\end{tabular}

Table 2. Comparing Services Time between Motorlance and Ambulance

Apiratwarakul @ 2022 Prehospital and Disaster Medicine

a Statistical significance.

\begin{tabular}{|c|c|c|c|}
\hline Feature & Category & Frequency & Percent \\
\hline \multirow[t]{2}{*}{ Gender } & Male & 25 & 54.3 \\
\hline & Female & 21 & 45.7 \\
\hline \multirow[t]{3}{*}{ Age Group } & $40-49$ & 9 & 19.6 \\
\hline & $50-59$ & 12 & 26.1 \\
\hline & $\geq 60$ & 25 & 54.3 \\
\hline \multirow{3}{*}{$\begin{array}{l}\text { Operation Time } \\
\text { (shift) }\end{array}$} & Morning & 12 & 26.1 \\
\hline & Afternoon & 18 & 39.1 \\
\hline & Night & 16 & 34.8 \\
\hline \multirow{2}{*}{$\begin{array}{l}\text { AED in Scene } \\
\text { Area }\end{array}$} & Yes & 1 & 2.2 \\
\hline & No & 45 & 97.8 \\
\hline $\begin{array}{l}\text { AED Access } \\
\text { Time (min) }\end{array}$ & Mean $(95 \% \mathrm{Cl})$ & \multicolumn{2}{|c|}{$5.02(4.48-5.10)$} \\
\hline \multirow{2}{*}{$\begin{array}{l}\text { Status Arrival at } \\
\text { Hospital }\end{array}$} & Continue CPR & 44 & 95.7 \\
\hline & Death & 2 & 4.3 \\
\hline
\end{tabular}

Apiratwarakul $\odot 2022$ Prehospital and Disaster Medicine

Table 3. Characteristics of the Subjects with AED Used in Motorlance $(\mathrm{N}=46)$

Abbreviations: AED, automated external defibrillator; CPR, cardiopulmonary resuscitation.

hospital policy to send a motorlance out to first check emergency patients in case there was a risk of contracting COVID-19, in which case they would arrange an ambulance with appropriate protective equipment to continue to take care of those patients. ${ }^{16}$

As for the operating shifts, most of the operations took place in the afternoon shift. This is consistent with previous studies. ${ }^{35-37}$ The main reason for this is the pattern of family relationships in Thai society that dictates that normally people of working age will go to work outside the accommodation, while their older parents will stay at home and take care of their grandchildren. ${ }^{38-40}$ This kind of pattern results in the elderly having symptoms of illness and having to wait for the parents to return to meet their children at home, and after that request assistance in the EMS setting. Therefore, most operations take place in the afternoon shift, which is the time after work.

For Thailand's EMS, there are personnel in operation consisting of a doctor, a nurse, a paramedic, AEMTs, and EMTs. The operation has two levels including advanced and basic. In the advanced operation level, there must be a doctor or nurse participating in the operation. An advanced-level deployment will occur when the patient's symptoms are notified and initial assessment is of critically ill patients; the command center will order the advanced operation. In the case of urgent symptoms or when immediate treatment is not necessary, they will be ordered to operate at the basic level of operations..$^{1-44}$

It was also found that when comparing the time in EMS from motorlance with the traditional ambulance in all shifts, activation time of the motorlance was shorter than the ambulance, which is consistent with previous studies. ${ }^{45,46}$ In this study, ambulance and motorlance parking spots were in the same area. Therefore, the shorter activation time of motorlance is due to the lower number of operational personnel (only two operational personnel), unlike an ambulance which requires four to five personnel to operate, thus making the length of time it takes for personnel to arrive at the vehicle different. However, according to EMS standards, the proper activation time should be less than two minutes, which shows the readiness of personnel to carry out operations with both models of emergency vehicles using less than two minutes. In terms of response time, motorlances took a shorter time to arrive at the scene than an ambulance. This is consistent with previous studies which point out one of the main benefits of a motorlance in that it is better able to move in a small street or in traffic jams. $5,7,9,16,47,48$ Most of the areas in this study were conducted within the university campus and surroundings which have different conditions of traffic routes. The university road has two to four traffic lanes, but in rush hour, there will be a lot of vehicles. In areas around the university, small alleyways and unmarked one-lane roads make up a majority of the grid, which in turn makes direction giving and routes to the patient complicated. Motorlances are clearly more advantageous in these types of environments. However, the period of EMS time (activation and response time) of motorlances and ambulances were shorter than the previous study, ${ }^{16}$ possibly due to the study period during the epidemic of the COVID-19 virus when traffic conditions were more flexible than usual, along with a number of students and staff working from home, causing the number of vehicles on the traffic route to decrease, resulting in access to patients faster than normal operations. ${ }^{39,42,45}$

In addition, the use of an AED on motorlances will be used in the event of a notification that there is an emergency patient who is unconscious, collapses, or stops breathing. Due to limitations of the installation of AEDs in public places, this study applied the new health policy of bringing an AED to be installed on a motorlance to solve two problems. Firstly, the lack of publicly installed AEDs, and secondly, the lack of expertise in using the equipment. It was found that the length of time to reach the patient is less than eight minutes, which is the standard assigned to the emergency medical unit to reach out-of-hospital cardiac arrest patients to increase the chance of survival. ${ }^{22,24,27}$ The study also found that almost all areas 
that reach emergency patients do not have AED equipment installed in public places, which corresponds to the nature of residence. Most of them live in one house or in an allotted village, which is far from the areas where an AED is located, such as a bus station or shopping mall. The modification of health policy will increase chances of survival of the people in the community. ${ }^{49,50} \mathrm{As}$ can clearly be seen from the study, almost all of the patients that are accessed with an AED-equipped motorlance have a chance to continue cardiopulmonary resuscitation (CPR) at the hospital. The health sustainable development policy with the use of a motorlance plays an important role in reducing access time to patients. In addition, the installation of the AED on the motorlance increases the chance of survival, which is considered a worthwhile investment. ${ }^{51,52}$ In countries with limited budgets, installing AEDs in public areas is an important policy that both the government and private sectors should pay attention to and jointly develop, but during the waiting period for development, the application of available resources by bringing a motorlance to install an AED would be beneficial to people in the community, especially patients with out-of-hospital cardiac arrest. In addition, the role of motorlances differs depending on the context of each country, such as in European countries, a motorlance will be used for assessment of disaster situations to assess if the area is safe. This includes early access to assess the resources needed at the scene. In Korea, a motorlance was used to reach out-of-hospital cardiac arrest patients to increase chances of survival. In African countries, motorlances were used to bring pregnant women to undergo antenatal care at community health centers, including taking pregnant women to deliver their babies at the hospital. Not surprisingly, motorlances are significantly cheaper to acquire and operate when compared with ambulances in the form of regular cars. Therefore, it is a new challenge in applying motorcycles to perform duties in the development of public health policies, especially in large urban areas with traffic congestion.

There may be some modifications to the vehicle configuration from a motorcycle to another form of three-wheel vehicle (Tuk Tuk) which is unique to Thailand, larger than a motorcycle but smaller than a car. The Tuk Tuk can solve emergency situations that motorcycles cannot, such as operating during heavy rain or strong winds. The Tuk Tuk can install rainproof plastic to prevent rain, resulting in a greater ability to perform and create a better environment for the operator and the emergency patients. Further developments such as telemedicine systems may be installed, such as a real-time camera recording so EMS members or doctors who are stationed at the hospital can see the patient's condition to be assessed promptly and deliver a timelier treatment, including possibly installing a navigation system from the hospital to the scene by using the shortest travel time.

\section{Limitations}

Limitations of the vehicle found that motorlances are unable to operate in conditions of severe rain, poor visibility, or during severe wind breaks because it may be dangerous to the operator. It was also found that at a distance of more than ten kilometers, the operations with a motorlance take a similar amount of time to reach the patient as an ambulance. Therefore, in such cases, the use of an ambulance is more beneficial in terms of its ability to transport patients. Limitation of the study was data collection gathered from a single EMS, which may look at the study population differently from other agencies. Therefore, information should be collected from many study agencies.

\section{Conclusions}

The operation time, including both in terms of time after receiving the notification call to vehicle (activation time) as well as traveling from the hospital to the scene (response time), of a motorlance was shorter than a conventional ambulance. The use of AEDs on motorlances in public areas without AEDs can increase the number of continuous resuscitations in out-of-hospital cardiac arrest patients.

\section{Acknowledgment}

The authors would like to express their sincere gratitude to Josh Macknick for acting as an English consultant.

\section{References}

1. Peleg K, Pliskin JS. A geographic information system simulation model of EMS: reducing ambulance response time. Am J Emerg Med. 2004;22(3):164-170.

2. Bahadori M, Ghardashi F, Izadi AR, Ravangard R, Mirhashemi S, Hosseini SM. Prehospital emergency in Iran: a systematic review. Trauma Mon. 2016;21(2):e31382.

3. Soares-Oliveira M, Egipto P, Costa I, Cunha-Ribeiro LM. Emergency motorcycle: has it a place in a medical emergency system? Am J Emerg Med. 2007;25(6):620-622.

4. Jafari M, Shakeri K, Mahmoudian P, Bathaei SA. Innovation in the use of motor ambulance for prehospital emergency care. J Educ Health Promot. 2019;8:38.

5. Kiefe CC, Soares-Oliveira M. Medical emergency motorcycles: are they safe? Eur J Emerg Med. 2008;15(1):40-42.

6. Hofman JJ, Dzimadzi C, Lungu K, Ratsma EY, Hussein J. Motorcycle ambulances for referral of obstetric emergencies in rural Malawi: do they reduce delay and what do they cost? Int J Gynaecol Obstet. 2008;102(2):191-197.

7. Riley P. Motorcycle medics. JEMS. 2000;25(12):32-41.

8. Pons PT, Haukoos JS, Bludworth W, Cribley T, Pons KA, Markovchick VJ. Paramedic response time: does it affect patient survival? Acad Emerg Med. 2005;12(7):594-600.

9. Chinprasatsak S, Satthapong S, Kotruchin P, Maporn K. Telegraphic medicine systems improve medical diagnosis in prehospital settings: a pilot study in a tertiary care hospital. J Med Assoc Thai. 2017;100:686.

10. Bigdeli M, Khorasani-Zavareh D, Mohammadi R. Prehospital care time intervals among victims of road traffic injuries in Iran. A cross-sectional study. BMC Public Health. 2010;10:406.

11. Vukmir RB. Survival from prehospital cardiac arrest is critically dependent upon response time. Resuscitation. 2006;69(2):229-234.
12. Dennis RA. Low-cost ambulance for developing countries. 5th IET Seminar on Appropriate Healthcare Technologies for Developing Countries. 2008;1-7.

13. Peyravi MR, Toubaei F, Pourmohammadi K. The efficiency of motorlance in comparison with ambulance in Shiraz, southern Iran. IRCMJ. 2009;3(11):330-333.

14. Wilson A, Hillman S, Rosato M, et al. A systematic review and thematic synthesis of qualitative studies on maternal emergency transport in low- and middle-income countries. Int J Gynaecol Obstet. 2013;122(3):192-201.

15. Ssebunya R, Matovu JKB. Factors associated with utilization of motorcycle ambulances by pregnant women in rural eastern Uganda: a cross-sectional study. BMC Pregnancy Childbirth. 2016;16:46.

16. Apiratwarakul K, Ienghong K, Mitsungnern T, Kotruchin P, Phungoen P, Bhudhisawasdi V. Use of a motorlance to deliver emergency medical services: a prospective cross-sectional study. Arch Acad Emerg Med. 2019;7(1):e48.

17. Ehiri J, Alaofe H, Asaolu I, Chebet J, Esu E, Meremikwu M. Emergency transportation interventions for reducing adverse pregnancy outcomes in low- and middleincome countries: a systematic review protocol. Syst Rev. 2018;7(1):65.

18. Apiratwarakul K, Ienghong K, Bhudhisawasdi V, Gaysonsiri D, Tiamkao S. Response times of motorcycle ambulances during the COVID-19 pandemic. Open Access Maced J Med Sci. 2020;8(T1):526-529.

19. Alarcón-Bernal ZE, Aceves-García R, Rojas-Arce JL. Location of bases for prehospital services. In data analysis and optimization for engineering and computing problems. Springer, Charm. 2020;73-84.

20. Apiratwarakul K, Ienghong K, Gaysonsiri D, Buranasakda M, Bhudhisawasdi V, Tiamkao S. Role of motorcycle-based ambulance (motorlance) in major sporting events. J Med Assoc Thai. 2020;103:15-17. 
21. Allan KS, Jefkins TT, O'Neil E, Dorian P, Lin S. Mandating training is not enough: the state of cardiopulmonary resuscitation and automated external defibrillator training in Ontario schools. CJC Open. 2021;3(6):822-826.

22. Milewski R, Sokołowska G, Jankowiak B, Kowalewska B, Milewski M, Lewko J. Is cluster analysis the appropriate statistical method for planning the optimal locations for automated external defibrillators? Stud Logic Grammar Rhetoric. 2020;64(1):7-14.

23. Smereka J, Aluchna M, Aluchna A, Szarpak $Ł$. Preparedness and attitudes toward medical emergencies in the dental office among Polish dentists. Int Dent J. 2019;69(4):321-328.

24. Smith CM, Griffiths F, Fothergill RT, Vlaev I, Perkins GD. Identifying and overcoming barriers to automated external defibrillator use by GoodSAM volunteer first responders in out-of-hospital cardiac arrest using the Theoretical Domains Framework and Behavior Change Wheel: a qualitative study. BMJ Open. 2020;10(3):e034908.

25. O'Callaghan PA, Swampillai J, Stiles MK. Availability of automated external defibrillators in Hamilton, New Zealand. N Z Med J. 2019;132(1503):75-82.

26. Rishipathak P, Bhandari M, Hinduja A. Retention of cognitive skills acquired in HeartSaver first aid CPR AED course of American Heart Association (AHA), USA among non-medical students in Pune City. Indian J Public Health Res Dev. 2019;10:742-744.

27. Post EG, Schaefer DA, Biese KM, et al. A comparison of emergency preparedness between high school coaches and club sport coaches. $J$ Athl Train. 2019;54(10):1074-1082.

28. Tunming $\mathrm{P}$, Chaigasem T, Siriwong $\mathrm{P}$. The increasing of potential in tourism logistics supply chain to Khon Kaen ME City, Thailand. Afr J Hosp Tour Leis. 2019;8:1-12.

29. Pathumporn J, Nakapaksin S. Accommodation management for integrated sustainable tourism management. Int J Sustain Dev Plan. 2016;3(11):236-244.

30. Kantawateera K, Naipinit A, Sakolnakorn TP, Kroeksakul P. Tourist transportation problems and guidelines for developing the tourism industry in Khon Kaen, Thailand. Asian Soc Sci. 2015;2(11):89-95.

31. Maneenetr T, Naipinit A, Tran TH. Guidelines to promote local community participation in developing agrotourism: a case study of Ban Mor Village, Sam Sung District, Khon Kaen Province, Thailand. Asian Soc Sci. 2014;10:178-186.

32. Al-Wathinani AM, Schwebel DC, Al-Nasser AH, et al. The prevalence of risky driving habits in Riyadh, Saudi Arabia. Sustainability. 2021;13:7338.

33. Thornton J. COVID-19: A\&E visits in England fall by $25 \%$ in week after lockdown. BMJ. 2020;369:m1401.

34. Apiratwarakul K, Kongudom N, Kotruchin P, Phungoen P. Visits to the emergency department during the 2020 COVID-19 outbreak in Thailand. J Med Assoc Thai. 2021;104: S1-S4.

35. Faramand Z, Frisch SO, Martin-Gill C, et al. Diurnal, weekly, and seasonal variations of chest pain in patients transported by emergency medical services. Emerg Med J. 2019;36(10):601-607.

36. Maudet L, Sarasin F, Dami F, Carron PN, Pasquier M. Urgences préhospitalières: crise COVID-19 [Emergency Medical Services: COVID-19 crisis]. Rev Med Suisse. 2020;16(N 691-692):810-814.
37. Croda JHR, Garcia LP. Immediate health surveillance response to COVID-19 epidemic. Resposta imediata da Vigilância em Saúde à epidemia da COVID-19. Epidemiol Serv Saude. 2020;29(1):e2020002.

38. Thanapop S, Thanapop C. Work ability of Thai older workers in Southern Thailand: a comparison of formal and informal sectors. BMC Public Health. 2021;21(1):1218.

39. Suratana S, Tamornpark R, Apidechkul T, et al. Impacts of and survival adaptations to the COVID-19 pandemic among the hill tribe population of northern Thailand: a qualitative study. PLoS One. 2021;16(6):e0252326.

40. Bhuanantanondh P, Buchholz B, Arphorn S, Kongtip P, Woskie S. The prevalence of and risk factors associated with musculoskeletal disorders in Thai Oil Palm Harvesting Workers: a cross-sectional study. Int J Environ Res Public Health. 2021;18(10):5474.

41. Pattanarattanamolee R, Sanglun RY, Nakahara S. Community-based first responder network in Rural Thailand: a case study of out-of-hospital cardiac arrest. Prehosp Disaster Med. 2021;36(2):234-236.

42. Prommoon P, Phibalsak T, Netwachirakul J, Mekthat M, Jitpiboon W, Sangthong R. Epidemiological characteristics of traffic and non-traffic injuries and quality of emergency medical services in Southern Thailand. J Health Sci Med Res. 2021;39:273-282.

43. Pochaisan O, Pattanarattanamolee R, Pongphuttha W, Chadbunchachai W, Nakahara S. Development of an emergency medical services system in Thailand: roles of the universal health coverage and the national lead agency. Emerg Med Australas. 2021;33:1-3.

44. Riyapan S, Chantanakomes J, Ruangsomboon O, et al. Assessment of prehospital management of patients transported to a Thai University Hospital. Siriraj Med J. 2020;72:287-295.

45. Alanazy ARM, Fraser J, Wark S. Organizational factors affecting emergency medical services' performance in rural and urban areas of Saudi Arabia. BMC Health Serv Res. 2021;21(1):562.

46. Kelker H, Yoder K, Musey P Jr, et al. Prospective study of emergency medicine provider wellness across ten academic and community hospitals during the initial surge of the COVID-19 pandemic. BMC Emerg Med. 2021;21(1):36.

47. Alassaf W, Al Hamid S, Kentab O, Al Otaibi A, Al Mufareh B. EMS operation in a female restricted university, Saudi prospective. Int J Emerg Med. 2021;14(1):16.

48. Walker KJ, Jiarpakdee J, Loupis A, et al. Predicting ambulance patient wait times: a multicenter derivation and validation study. Ann Emerg Med. 2021;78(1):113-122.

49. Sekendiz B. Incidence, bystander emergency response management and outcomes of out-of-hospital cardiac arrest at exercise and sport facilities in Australia. Emerg Med Australas. 2021;33(1):100-106.

50. Pemberton K, Bosley E, Franklin RC, Watt K. Epidemiology of prehospital outcomes of out-of-hospital cardiac arrest in Queensland, Australia. Emerg Med Australas. 2019;31(5):821-829.

51. Abelairas-Gómez C, Schroeder DC, Carballo-Fazanes A, et al. KIDS SAVE LIVES in schools: cross-sectional survey of schoolteachers. Eur J Pediatr. 2021;180(7):22132221.

52. Nakagawa NK, Oliveira KMG, Lockey A, et al. Effectiveness of the 40-minute handmade manikin program to teach hands-on cardiopulmonary resuscitation at school communities. Am J Cardiol. 2021;139:126-130. 